the unknowable organic process, whatever it may be) may exist for a number of years without being recognized. He fully emphasizes that the symptoms of the clinical pictures are determined by the complex. No woman, who is not longing for children or fears childbirth, will react to hallucinations or delusions governed by the content of such a complex. It is utterly impossible to conceive how symptoms may develop without psychical causes. Jung agrees with Blueler that the content of the complex modifies the symptoms in dementia pracox. The acute attacks, exacerbations, aggravations, remissions, etc., frequently arise from psychological causes and most probably reactionary to peculiar brain disposition.

Jung is not exactly clear about the latency in dementia præcox, the so-called organic process, and the limitations between primary and secondary symptoms. He thinks, with Bletler, that dementia præcox may develop from psychological grounds into an organic process. In the words of Jung: "An influence of an effect, like any psychical cause, can loosen the organic process of dementia precox (through toxins) and indeed simulating the manifestation of tuberculosis in a contused joint. The disease develops in a locus minoris resistentic, that is, in dementia præcox the entire physical like the psychical disease process can develop from an affective complex, exactly like under any other conditions from psychical trauma, infection, etc. If the complex were not in such a case, then the peculiar disease would not develop under these circumstances. Therefore, for such cases, the complex had not only the usual determinant as far as its content is concerned, but also a significance for the origin of the organic process."

MoRris J. Karpas.

\title{
Journal de Psychologie, Normale et Pathologique
}

(Fifth year. No. 3. May-June, Ig08)

I. One Form of Combined Psychasthenia and Delirium. F. L. Arnaud.

2. The Influence of the Chinese Language upon that Nation's Mentality. LEGRAND.

3. Note upon Individual Auto-mutilation. Charles Brondel.

I. Combined Psychasthenia and Delirium.-. It is less than twenty years since alienists almost universally agreed that there existed a profound incompatibility between so-called conscious obsessions and a true delirium. The delirious and the obsessed constituted two classes of cases utterly exclusive of one another. Under the influence of numerous writings, French as well as foreign, published during the last few years, a complete change has been wrought in the above opinion, so that there is scarcely a person today who does not admit, not merely the possibility but the frequent observation of, the actual combination of obsessional and delirious states.

Before the Congress of Geneva-Lausanne, Arnaud alluded to three principal forms or modes of association between delirium and psychasthenia, a disease of obsessions, without provoking the least adverse criticism. He described.the first as the delirious crisis, appearing very abruptly. Here the delirium overwhelms and masks the symptoms of the obsessional state so that the latter is unrecognizable. Ultimately, however, the crisis vanishes and the previous mental state reappears. One might speak of this as a delirious accident occurring in a psychasthenic 
just as it might have occurred in any other predisposed patient. The second class of associated delirium and obsessions includes cases in which the two sets of symptoms coēxist very clearly, remaining very distinct from each other, and having a more or less slight and logical connection with one another in such a way as to render the clinical picture of the association exceedingly complex. Here, as Falret and most authors after him declare, the delirium is one of persecution with tendencies toward melancholia. It develops gradually, becomes fixed and systematized, and terminates in a definite chronicity. Dissimilar as the two preceding modes of combination are from the clinical point of view, they nevertheless possess a uniform characteristic from the psychological standpoint. The delirium, whatever its relations to the obsessional state may be, is always composed of elements, in both cases, distinct from the accompanying obsessions, elements wholly extrinsic and in a measure quite foreign to the obsessions. Hence there is a complicating of one mental state by another mental state, the nature of which is decidedly different.

The third mode of combination, to which the present article is especially devoted and which the author illustrates with three clinical reports, includes those cases wherein the deliritum, in all of its essential traits, has its roots wholly in the obsessional state; or, to be more definite, is constituted of the very obsessions themselves, the manifestation of which is carried to such a high degree of exaggeration. The delirious ideas here preserve all the general features of the ordinary obsessions of psychasthenia. This is the reason why the author, in collaboration with Professor Raymond, has named this form of delirium psychasthenic, delirious psychasthenia.

2. The Infuence of the Chinese Language upon the Nation's Mentality. -A long but interesting article, to indicate how the inflexibility of the Chinese langtuage has had much to do in stultifying and retarding the mental processes and mental development of the nation as a whole.

3. Individual Auto-mutilation.-Blondel finds that self-mutilation is not a special symptom of any one form of mental trouble. The conditions only under which it has been practised are occasionally able, as the result of a searching examination, to reveal the reason for it. The atthor points out some of the commoner forms of self-mutilation. He applies the term indirect self-mutilation to those cases wherein an importunate individual, mentally defective, succeeds in persuading a surgcon to perform upon him an unnecessary operation. The suggestive remark is made in closing by the author that such indirect self-mutilation "most obviously needs the concurrence of two diseased wills, for one volition, when manifestly diseased, can only secure the coöperation of another volition when that is likewise more or less debilitated."

Mettler (Chicago).

\section{Miscellany}

Cuninical and Anatomical Study of Multiple Sclerosis. Raymond and Rajes. (L'Encephale, Vol. II.)

A case with autopsy, where besides old lesions, those in process of formation were found explanatory of the mode of invasion. In the course of the disease an edema occurred which the authors believe to have been trophic. It began spontaneously two years and a quarter before death by weakness of the legs, clumsiness of the hands and failing vision. These symptoms remitted after about six months, to reappear a month later. 